Article

\title{
'Fake News' in Science Communication: Emotions and Strategies of Coping with Dissonance Online
}

\author{
Monika Taddicken * and Laura Wolff \\ E-Mails: m.taddicken@tu-braunschweig.de (M.T.), laura.wolff@tu-braunschweig.de (L.W.) \\ * Corresponding author \\ Submitted: 26 September 2019 | Accepted: 17 December 2019 | Published: 18 March 2020
}

Department of Communication and Media Sciences, Technische Universität Braunschweig, 38106 Braunschweig, Germany;

\begin{abstract}
In view of events such as the public denial of climate change research by well-known politicians, the effects of postfactual disinformation and emotionalisation are discussed for science. Here, so-called 'fake news' are of focus. These are considered problematic, particularly in a high-choice media environment as users tend to show selective behaviour. Much research has demonstrated this selective exposure approach, which has roots in the Theory of Cognitive Dissonance (Festinger, 1957). However, research on the processes of coping with dissonance is still considered sparse. In particular, communication scholars have overlooked emotional states and negotiations. This article analyses the affects that are aroused when users are confronted with opinion-challenging disinformation and how they (emotionally) cope by using different strategies for online information. For this, we used the context of climate change that is widely accepted in Germany. The innovative research design included pre- and post-survey research, stimulus exposure (denying 'fake news'), observations, and retrospective interviews $(n=50)$. Through this, we find that perceptions and coping strategies vary individually and that overt behaviour, such as searching for counter-arguments, should be seen against the background of individual ideas and motivations, such as believing in an easy rejection of arguments. Confirming neuroscientific findings, participants felt relieved and satisfied once they were able to dissolve their dissonant state and negative arousal. Dissatisfaction and frustration were expressed if this had not been accomplished.
\end{abstract}

\section{Keywords}

cognitive dissonance; emotions; fake news; online disinformation; science communication; selective exposure

Issue

This article is part of the issue "Emotions and Emotional Appeals in Science Communication" edited by Monika Taddicken and Anne Reif (Technische Universität Braunschweig, Germany).

(C) 2020 by the authors; licensee Cogitatio (Lisbon, Portugal). This article is licensed under a Creative Commons Attribution 4.0 International License (CC BY).

\section{Introduction: Science Information Online}

Several problems and threats for individuals and society around the consumption of online information have been recently debated. In view of events such as the public denial of climate change research by well-known politicians, the effects of disinformation are discussed. However, disinformation should not be confused with misinformation. The latter is information that is incorrect, possibly given by accident, but not created with the intention of causing harm, whereas disinformation means intentionally false information that is often used for spe- cific communication strategies, such as damaging the reputation of a person, social groups, organisations or countries (cf. Garrett, 2017). Among these are so-called 'fake news.' Although there is no universal understanding of 'fake news,' some aspects appear to be central: deliberately false claims that are supposed to imitate the style of conventional media reporting and to reach a certain public (Gelfert, 2018; Zimmermann \& Kohring, 2018; see also Ethical Journalism Network, n.d.; First Draft, n.d.)

Facing the fact that we live in a high-choice media environment, their existence is considered problematic. It is assumed that users confirm their own opinions 
many times over, regardless of whether they are scientifically founded or socially established (so-called confirmation bias). Expectations of 'filter bubbles' (Pariser, 2011), 'information cocoons' (Sunstein, 2018), or 'echo chambers' (Sunstein, 2001) raise concerns about narrowminded online users and societal fragmentations and polarisations. However, at the same time-and this is often forgotten-it is highly likely that users will come into contact with online content that contradicts or challenges their own attitudes. The enormous diversity of opinions, values, and beliefs presented online allows for a much higher proximity to opposing opinions through users' social networks.

The effects of a high-choice media environment are mainly discussed over information about politics and public issues; however, the relevance of science information for society is increasingly acknowledged. Thus, Scheufele and Krause (2019) demand urgent research on the (mis/dis)information of scientific issues and analyses of science communication in new media environments.

This article aims to contribute to this goal by considering Festinger's (1957) Theory of Cognitive Dissonance (TCD), which can be seen as the root of research on selective exposure theory. A wide variety of empirical studies has proven the assumption that online users turn primarily to content that confirms their own attitudes (D'Alessio \& Allen, 2007; Knobloch-Westerwick \& Kleinman, 2011). Nevertheless, according to recent studies, users do not necessarily turn away from content that contradicts or challenges their attitudes (Garrett, 2017; Jang, 2014). However, research on the processes of coping with dissonance is still sparse.

Further, and this is quite new to research on cognitive dissonance and for the field of science communication, we will consider the emotional states and negotiations of online users. Online and social media are discussed as problematic due to their emotional-impulsive functional logic that favours the spread of polarising and pointed rhetoric (Eisenegger, 2017). This is related to the rational argument, discourse, and deliberation perspective of Habermas (1990) on public spheres and communication, which is widespread in scholarly discussion. However, recent concepts of 'affective publics' (Papacharissi, 2014) have argued over the relevance of considering affects because this allows focus on relational, processual, and performative aspects, and thus provides broader understanding (Lünenborg, 2019).

According to the common perspective on rationality and cognitive processes, prior studies in the field of dissonance research typically focus on cognitive negotiation whereby, according to the TCD, the emotional sensation after reception plays an important role. The emotional state of a human being can affect the accuracy of his or her beliefs. In recent experimental work, it was found that angry partisans who saw uncorrected political misinformation from their own party held less accurate beliefs than emotionally neutral partisans. This raises concerns that anger can facilitate belief in falsehoods (Scheufele
\& Krause, 2019; Weeks, 2015). Emotional states, and anger in particular, are assumed to interact with individual ideologies and the information environmentsuch as the presence or absence of correctives - to influence how people encounter ( $\mathrm{mis} / \mathrm{dis}$ )information. Thus, potentially exacerbating their beliefs in falsehoods and shaping how (mis/dis)information is assimilated into their own worldviews (Scheufele \& Krause, 2019).

This study aims to shed light on questions over how people are emotionally affected by online disinformation and how they cope by using different strategies for online information.

\section{Coping with Dissonance}

In his TCD, Festinger (1957) assumes that people strive for inner psychological consistency. Cognitive dissonance describes a person's mental discomfort that is triggered by a situation in which one is confronted with facts that contradict his or her beliefs, ideals, and values. Basic hypotheses of the TCD (Festinger, 1957, p. 3) are:

1. The existence of dissonance, being psychologically uncomfortable, will motivate the person to try to reduce the dissonance and achieve consonance.

2. When dissonance is present, in addition to trying to reduce it, the person will actively avoid situations and information which would likely increase the dissonance.

Festinger assumes observable manifestations of these pressures (Festinger, 1957). It is important to acknowledge that the state of cognitive dissonance is an aversive motivational state of personal stress (Elliot \& Devine, 1994; Harmon-Jones, Harmon-Jones, \& Levy, 2015) and it causes negative affect (Harmon-Jones, 2000a). Getting into a dissonant state by being confronted with attitudeinconsistent cognitions initially produces a negative emotional reaction (Garrett, Carnahan, \& Lynch, 2013). However, even though this imbalance is caused by a conflict on the cognitive level, experiencing this state encompasses the affective level, including a certain level of arousal. These may vary individually and can arise from the mere presence of a cognitive conflict or from a self-threat, such as the perception that one is poorly informed (Hart et al., 2009). Although cognitive discrepancy and the resulting negative emotions are interacting in the state of dissonance, one can analytically differentiate between behaviour that seeks to reduce the cognitive discrepancy and behaviour of coping with the negative emotional state (Harmon-Jones, 2000b). Surprisingly, although the idea that cognitive dissonance can create an unpleasant feeling is central to the TCD, this is mostly overlooked in research studies (Harmon-Jones, 2000a). Therefore, this study will focus on this emotional perspective.

Looking at information selection behaviour, the desire for cognitive balance was assumed to induce people 
to expose themselves to certain types of media content in preference to others, which is well-known as selective exposure hypothesis (D'Alessio \& Allen, 2007). In particular, the idea of confirmation-biased selective exposure has long been discussed (Knobloch-Westerwick \& Kleinman, 2011). Where empirical studies have oftentimes confirmed the selective exposure towards congruent information, particularly regarding political issues, recent studies have not confirmed the systematic avoidance of incongruent information (Garrett, 2017; Jang, 2014).

However, most empirical research has been carried out on an individual's behaviour to avoid dissonance or incongruent information. Donsbach (2007) has criticised that previous research usually leaves open how people actually handle a situation when confronted with incongruent information, which mostly fails to take into account that dissonance only arises under these conditions. That is why this study will focus on how people cope with their state of dissonance. Individuals do not passively accept this negative state; instead, they engage in either counter-arguments or search for ways to discount or ignore the offending information (Festinger, 1957; Garrett et al., 2013). If the individual is successful in these efforts, and the contradiction between attitude and discrepant evidence is resolved, an individual will feel rewarded or relieved (Garrett et al., 2013). This was shown in a neuroscience study, where areas of the brain associated with pleasure were activated when the challenging information was successfully equilibrated to an emotionally stable judgment (Westen, Blagov, Harenski, Kilts, \& Hamann, 2006 , p. 1956). Thus, the negative emotional state triggered by counter-attitudinal exposure tends to be shortlived, and successful rejection of the challenge is emotionally rewarding (Garrett et al., 2013).

However, research on the emotional dimension of being confronted with counter-attitudinal information and becoming imbalanced is rare, and even more so is research on how individuals cope with their dissonance, particularly regarding emotional processes. This study focuses on these research questions in the context of 'fake news' exposure. Consequently, this study is guided by the following research questions:

RQ1: What affects do internet users have when confronted with opinion-challenging disinformation?

RQ2: How do they cope with their state of dissonance?

We will use the term 'affect' to cover the arousal and valence of emotions. Whereas (psychological) research has put much effort into theorising and differentiating emotions and affects, it is often criticised that distinctions between affect and emotion are untenable (in communication and media studies; Lünenborg \& Maier, 2018). Thus, affect and emotion are often considered as synonymous (Lünenborg, Maier, \& Töpper, 2018). Particularly in research on media use and effects, affect usually covers emotions and is discussed regarding aspects of (de)arousal or (de)activation and valence, such as varying degrees of positive-negative or pleasuredispleasure (Konijn, 2013, p. 190; Wirth, 2013, p. 229), as followed here.

Moreover, we will use the term of coping with dissonance instead of reducing. With this, we highlight interests in the processual perspective on individuals' behaviour and their ways of dealing with psychological discomfort (Diestel \& Schmidt, 2011; Fogel, 2004).

For our research questions, the highly relevant public issue of climate change is an appropriate context as the phenomena of 'fake news'/mis- and disinformation, filter bubbles, and polarisations are widely discussed on this issue (Fisher, Waggle, \& Leifeld, 2012; van der Linden, Leiserowitz, Rosenthal, \& Maibach, 2017; Williams, McMurray, Kurz, \& Hugo Lambert, 2015).

\section{Methods}

To explore emotional processes and coping strategies in more depth than in previous research, this study triangulates quantitative and qualitative methods in an innovative research design through the use of surveys, eye tracking, and a post-exposure walkthrough during retrospective interviews (see Figure 1).

In a laboratory setting, university students ( $n=50$, aged between 19 and 38 years [ $M=23.2 ; S D=3.5$ ], mostly female [70\%], see Supplementary File) were exposed to a stimulus: a YouTube clip titled "The big $\mathrm{CO}_{2}$ lie explained in 3 minutes, simple and comprehensible," produced by kla.tv (short for Klagemauer TV [Wailing Wall TV]), that proclaims doubts about humans' responsibility for causing climate change (Kla.tv., 2014). For example, the so-called 'Oregon Petition' is presented, according to which scientific research has not proven that high amounts of $\mathrm{CO}_{2}$ contribute to global warming. This petition was rejected by the National Academy of Sciences in the US (The National Academies of Sciences, Engineering, and Medicine, 1998). Moreover, the 'Heidelberg Appeal' is presented as a statement against man-made climate change, although the Heidelberg Appeal is "a quiet call for reason and a recognition of scientific progress as the solution to, not the cause of, the health and environmental problems that we face" (DeWeese, 2002). Kla.tv (n.d.) introduces itself with "Klagemauer TV entlarvt

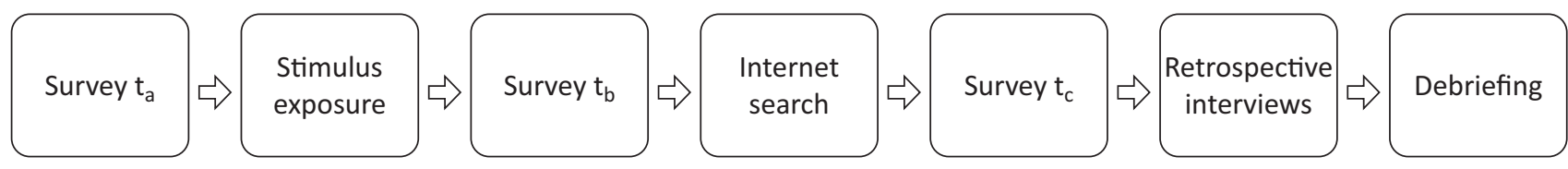

Figure 1. Procedure of the study. 
Verderben bringende Medienlügen und Lügenmedien!" ("Wailing Wall TV exposes spoiling media lies and lie media!"), indicating a conspiracy background.

Subsequently, the participants were given $10 \mathrm{~min}$ utes to perform an internet search that was not restricted to the issue of climate change. Standardised surveys were conducted before the lab stage $\left(t_{a}\right.$ : paperbased, about two weeks before), directly after 'fake news' exposure and before the online research $\left(t_{b}\right.$ : online), and after the online research ( $t_{c}$ : online). Here, we asked-inter alia-for climate change attitudes $\left(t_{a}, t_{c}\right)$. As emotions are at the centre of the research, this study is mainly interested in affective attitude components. Therefore, we will analyse an individual's climate change problem awareness (reduced scale of Taddicken \& Reif, 2016), first introduced by Taddicken (2013). For measuring the immediate state of dissonance, we conducted in $t_{b}$ positive and negative affects by means of the German version (Breyer \& Bluemke, 2016) of the widely used Positive and Negative Affect Schedule (PANAS) scale (Watson, Clark, \& Tellegen, 1988). It is supplemented by three more items particularly interesting in this context. The online research phase was recorded through an eye tracking system. This recording was then used as a stimulus for a post-exposure walkthrough. Participants were asked at this stage to explain their choice of keywords and web pages. These retrospective interviews lasted between 11 and 30 minutes. Finally, a debriefing document was given to the participants. In this document, popular climate change denying arguments were briefly discussed using parts of the IPCC report (BMU, UBA, \& German IPCC Coordination Unit, 2017).

To ensure that the stimulus was opinion-challenging for participants, we excluded those who did not fully believe in human-made climate change. The final sample size was $n=39$.

The conducted survey data were used to calculate different statistical tests (principal component analysis [PCA], analysis of variance [ANOVA]). The transcripts of the interviews were analysed qualitatively using a deductive-inductive approach, starting with the methodology of Grounded Theory (Glaser \& Strauss, 1999). Following the guidelines of Corbin and Strauss (1990), open coding was used first to identify conceptually perceptions, actions, and emotions. They were grouped together to form categories and subcategories. These were then related to different stages during the online research phase according to user-centred approaches of information seeking (Kuhlthau, 1991) and, moreover, to different stages of the process of coping with dissonances (Festinger, 1957).

\section{Results}

\subsection{Research Question 1 on Affects}

RQ1: What affects do internet users have when confronted with opinion-challenging disinformation?
To answer RQ1, we looked at the data of the PANAS scale first. Supplementary to the original 20 items were three items interesting in this context: 'confirmed' as a positive affect item and 'confused' and 'insecure' as negative affect items.

Overall, the participants were more negatively affected than positively, which is not surprising as the stimulus was opinion-challenging and of negative tone. What is interesting is the small difference between both affect dimensions and the general level of affect, which is below the middle of the five-point rating scale. The items 'irritable' and 'hostile' of the negative dimension show the highest scores of standard deviations, with answers ranging from 1 to 5 , meaning that some participants felt very irritable or hostile while others did not. Thus, individual reactions to the stimulus varied widely (see Supplementary File).

To explore these differences more deeply, we calculated a PCA to further differentiate the emotional states of dissonance. Three different factors were identified: anger, alarm, and activation (see Table 1). In this solution, three of the original positive affect items were not included as their means and standard deviations were both very low.

The first factor explaining the highest proportion of variance is anger, with the highest loadings of feeling 'irritable,' 'hostile,' and 'upset.' The second factor is alarm, with being 'afraid,' 'nervous,' and 'insecure' loading the highest. Both factors are mixed between items of positive and negative affect of the original PANAS scale. The third factor, activation, is composed of only positive affect items, such as 'active,' 'attentive,' and 'alert.' The originally positive affect item 'strong' loads on anger, which indicates that participants felt angry but not weak or defensive. The originally positive affect items 'interested' and 'inspired' load on alarm, which indicates that the feeling of being alarmed by the disinformation also seems to have some elements of curiosity.

In general, the means indicate a medium to low affect level, even though being angry and feeling alarmed by the stimulus is higher than the feeling of being activated by the video (see Table 2 ).

From these data, we do not know why some participants felt angry, alarmed or activated, and it remains unclear what explicitly caused the affective arousal: the presented content, the format, or the provider. To explore this in more detail, the reconstructive interviews were analysed. The interviews were held in German. Selected citations were translated for this article.

Anger: This had the highest share in explained variances and it became clear that some individuals recognised the stimulus as disinformation and this caused avoidance:

Because this is bullshit. So....Because I simply don't believe anything about it and just felt mucked about by the presentation alone and just don't want to listen to such right-winged nonsense. (P35) 
Table 1. PCA of affect items.

\begin{tabular}{|c|c|c|c|}
\hline Items & Anger & Alarm & Activation \\
\hline irritable (n) & .868 & & \\
\hline hostile (n) & .812 & & \\
\hline upset (n) & .791 & & \\
\hline ashamed (n) & .628 & & \\
\hline strong $(p)$ & .541 & & .449 \\
\hline confused * & .465 & .427 & \\
\hline afraid (n) & & .688 & \\
\hline nervous (n) & & .687 & \\
\hline insecure * & & .638 & \\
\hline jittery (n) & & .609 & \\
\hline distressed (n) & & .579 & \\
\hline interested (p) & & .560 & \\
\hline inspired (p) & & .502 & .428 \\
\hline scared (n) & & .500 & \\
\hline active (p) & & & .604 \\
\hline attentive (p) & & & .598 \\
\hline alert $(p)$ & .443 & & .551 \\
\hline confirmed $*$ & & & .512 \\
\hline determined (p) & .447 & & .497 \\
\hline guilty $(n)$ & & & .455 \\
\hline \multirow{3}{*}{\multicolumn{4}{|c|}{$\begin{array}{l}\text { enthusiastic }(p) \\
\text { excited }(p) \\
\text { proud }(p)\end{array}$}} \\
\hline & & & \\
\hline & & & \\
\hline Eigenvalue & 5.433 & 2.848 & 2.152 \\
\hline Explained variances & $23.6 \%$ & $12.4 \%$ & $9.4 \%$ \\
\hline Cronbach's Alpha & .820 & .787 & .723 \\
\hline
\end{tabular}

Notes: Elbow criterion, varimax rotation, factors <.4 shown; explained variance $45.4 \% ;$ p: positive, n: negative; ${ }^{*}$ additional items.

Compared to the cognitive discrepancy, the affective intensity of the dissonance experience becomes particularly obvious here. The stimulus was seen as hostile content. In some cases, strong emotions were revealed, even anger against the study itself which forced the exposure:

First of all, I think I should have been warned that the study might trigger certain emotions. Because I'm really a bit pissed off now...that people don't realise that this is actually total bullshit what they are saying. That makes me really aggressive. (P45)

Participants felt annoyed by the idea that other people could believe in the presented content. They showed superior feelings towards these third persons with the more impressionable minds' (known as third-person- effect; Davison, 1983, p. 1). This goes along with the finding that the affect item 'strong' belongs to this factor.

Alarm: Besides, participants were alarmed, and feelings of uncertainty were expressed. Some individuals felt irritated and insecure:

Um, it surprised me, and I...err...would have said I didn't believe it, but it made me think a little. (P56)

Individuals revealed feelings of nervousness about their perceived insecurity:

And somehow she [the moderator] spoke like that....I don't know....It was like: Is she telling the truth or not? I really wasn't sure after the video how much truth there is in that. (P29)

Table 2. Descriptives of the introduced affect dimensions.

\begin{tabular}{lcccc}
\hline Factors & Mean & Standard deviation & Minimum & Maximum \\
\hline Anger & 2.32 & .801 & 1 & 4.13 \\
Alarm & 2.21 & .649 & 1.33 & 4.22 \\
Activation & 2.03 & .553 & 1.13 & 3.25 \\
\hline
\end{tabular}

Note: $\mathrm{n}=39$. 
Activation: States of activation were expressed as the motivation to seek for more information and to learn more about other perspectives on climate change:

And then she [the moderator] also gave facts and percentages....and um, the video definitely made me want to check things again. Because I don't watch a video and believe this to be the truth, but I want to see both sides....And that's why, yeah, I got active and thought, I'Il look myself what the net has to say about it. (P48)

Overall, the feeling of imbalance after stimulus exposure was 'only' medium to low; however, emotional responses were not only of a different kind, they were related to perceptions of different reference objects. Three different factors of affects were identified: anger, alarm, and activation. While overall anger was the dominant emotion, the feeling of insecurity and helplessness led to an alarmed state. Activated people mainly seemed curious about unknown and surprising arguments.

\subsection{Research Question 2 on Coping}

RQ2: How do they cope with their state of dissonance?

According to Festinger's (1957, pp. 19-22) original theory, individuals can cope with their state of dissonance through different strategies: (1) by adding consonant conditions that reduce the overall level of inconsistency and includes active attempts to seek out new information; (2) by decreasing the importance of the elements involved in the dissonant relations; or (3) by changing one of the dissonance elements, either attitudes, values, opinions, or behaviours (Simon, Greenberg, \& Brehm, 1995). Moreover, he assumes-when people are involuntarily confronted with information they would have normally avoided-(0) the "set up [of] quick defensive processes which prevent the new cognition from ever becoming firmly established" (Festinger, 1957, p. 136).

In this study, strategies (1) and (2) are the ones to favour from a normative perspective as these indicate 'fake news resistance' - the same for (0) quick defencewhereas (3) can be seen as democratically problematic.

Overall, participants used a variety of different keywords for their searches, but most often started with "Klimawandel" [climate change] or "Klimalüge" [lie about climate change].

\subsection{1. (0) Quick Defence}

It is plausible to assume that many of the participants used quick defensive processes to directly avoid the establishment of contra-anthropogenic climate change information. This might explain the relatively low level of dissonance of some individuals directly after exposure.

Throughout the interviews, participants used the expression of 'conspiracy' and 'conspiracy theory' several times and this often seemed to be connected to anger. One individual revealed this as a quick defence argument, but added that searching for counter-arguments was part of the coping strategy:

I instantly classified her [the moderator] as a conspiracy theorist...so my first search...was to look at all these arguments....It's always the same what the climate change opponents say. Um. Just to look again: Is there perhaps something true about it? But, well...if you already call it a conspiracy theory then it's clear that you're just confirming your own knowledge. (P45)

\subsection{2. (1) Adding Consonant Information}

In line with this strategy, individuals add consonant conditions to reduce the overall level of inconsistency, which includes active attempts to seek out new and confirming information.

While Germans generally perceive themselves to be fairly knowledgeable about climate change (Taddicken, Kohout, \& Hoppe, 2019), specific details in the clipmainly the named 'Heidelberg Appeal' and the 'Oregon Petition'-caused a desire to seek more information. Here, the participants obviously felt activated:

The researcher [the moderator] also talked about this...the Oregon...or so. And then I was really interested in how these numbers came about. (P27)

However, in this study participants mainly confirmed their attitudes with the help of reading already known information. This strategy was mainly confirming instead of discovering, which might have resulted from their affective state of anger. It is striking that participants were able to clearly recognise this strategy within their own behaviour and to explicitly express it:

I wanted to confirm that the information that was shown is false and that my previous knowledge is right. (P58)

Nevertheless, their defence motivation was satisfied by their selection:

Um, and I got exactly the information that interested me. So you can see that, like, 97 percent [who agree to anthropogenic climate change] is a very large majority, which then, like, which I didn't even know until then. That encouraged me again, like, to see that...there is not at all a fight in science, but that the situation is actually quite clear. (P31)

In sum, the search for concrete information aims to clarify and counter-argue the cited facts. This can be classified as a coping strategy with the aim to dissolve the state of dissonance by trying to overcome the cognitive discrepancy in the first place. 


\subsection{3. (2) Decrease Dissonant Elements}

The coping strategy of confirming was often merged with the strategy of decreasing dissonant information:

Well, I wanted to see what the opposing voices are actually about and above all I wanted to have a closer look at the proportion...because...I had the feeling that, um, there's a discrepancy. (P31)

In order to devalue dissonant elements, counterinformation can be actively sought and considered as helpful when an individual believes he or she can easily refute the information (Frey, 1981). This strategy was clearly used by some subjects:

I didn't want to hear any more opinions, I wanted to know what that Heidelberg Appeal or uprising or what it was called was....And then I was confirmed, so my opinion was confirmed, that climate change exists and that all these, apparently this Heidelberg Appeal thing is a conspiracy theory, too, in the end. And then I was actually satisfied with it. (P26)

Here, the refutation of dissonant information was used to cope with the dissonance instead of the naive avoidance of the given information. Confirmation that the presented information in the stimulus was not valuable produced a feeling of satisfaction and relief.

In contrast to those individuals who felt activated by the stimulus and interested to find out more about the contra-arguments, others were defensive and mainly or even only interested in discounting the stimulus:

I have to say, I wasn't really interested in the climate thing. I didn't...I didn't feel like confirming that climate change is real. It didn't make me feel like it at all...because I knew there was such a thing and I was really only interested in what kind of source it was. (P12)

Here, the coping strategy is to confirm one's own view by searching for information to discount the source's credibility. For this aim, content from the clip provider on other public issues was screened, such as denial of the Holocaust, which caused intense indignation with a much higher level of emotional arousal. However, although the success of the discounting was not perceived as surprising it did cause a certain feeling of satisfaction.

Another feeling caused by the stimulus exposure was amusement:

So, if I'd just seen it at home, I probably wouldn't have googled anything....At home I would have just thought: Ok, honestly, I would have just laughed it away. Maybe, and I think I also ticked [in the questionnaire] that I would share it. Maybe I'd even have shared it with somebody, like: "Hey, look how funny this is!" (P12)
This undermines the assumption that content-even with regard to public science issues-is more likely shared when it evokes surprise or disgust (Scheufele \& Krause, 2019; Vosoughi, Roy, \& Aral, 2018).

In sum, the participants used coping strategies to refute the stimulus content and discount its credibility. The subjects were less concerned with the (objective) negotiation of the cognitive discrepancy caused by any counterinformation. Their main focus was coping with the negative emotional state of dissonance, with feelings of relief and satisfaction being disclosed if that succeeded.

\subsection{4. (3) Changing Attitudes}

Whereas the former coping strategies can lead to 'fake news resistance,' the coping strategy of changing one of the individual's dissonance elements indicates a problematic consequence: when individuals change to lower problem awareness. We first calculated repeated measures ANOVA. This determines that the means of the index of climate change problem awareness shows a statistically significant difference between the measurements $(F(2,74)=8.324, p=.001)$. Looking at the single items, the means of three of the four items differed significantly between the three different data points. Thus, the stimulus exposure caused a significant decrease of problem awareness. Although this rallies at data point three, the means of problem awareness do not return to the initial level (see Table 3). We did not measure problem awareness after the reception of the debriefing document.

A power analysis was conducted with G*POWER (Faul, Erdfelder, Lang, \& Buchner, 2007). The post-hoc test for sensitivity for the repeated measures ANOVA showed an effect size of $\mathrm{f}=.36$ for 39 participants ( $\alpha$ err prob $=.05$, power $=.80$ ), with Critical $F=3.117$, indicating a medium to large effect (Cohen, 1988).

To investigate how many participants changed their affective attitude component problem awareness, we calculated the individual differences over the three data points to count the number of people with a decrease in problem awareness (see Table 4). Half of the participants showed a decrease of problem awareness after the stimulus reception $\left(t_{a}-t_{b}\right)$. For almost half of the subjects (17 of 38), this effect persists until after the research period (albeit reduced, cf. level of differences).

This result was surprising because we assumed participants would be mainly resistant. Therefore, we explored this more deeply by analysing the retrospective interviews of people with a permanent decrease in problem awareness over the three data points. Different search intentions and behaviours were found in this group of participants.

It became clear that some individuals felt lost in their state of dissonance as they tried to seek out objective information, but were not sure over how to exactly find the information. Participant P04 is a good example: She wanted to "find out if this is really such an alleged lie" and was "trying to find anything scientific about it." She 
Table 3. Repeated measurement of climate change problem awareness.

\begin{tabular}{|c|c|c|c|c|c|}
\hline & $\begin{array}{l}t_{a}: \text { before the } \\
\text { exposure }\end{array}$ & $\begin{array}{l}t_{b}: \text { directly after } \\
\text { the exposure }\end{array}$ & $\begin{array}{c}t_{c}: \text { after the internet } \\
\text { research }\end{array}$ & & \\
\hline Item & Mean (SD) & Mean (SD) & Mean (SD) & $\mathrm{F}$ & $\mathrm{p}$ \\
\hline Climate change problem awareness. & $4.55(.526)$ & $4.34(.696)$ & $4.34(.608)$ & 8.324 & .001 \\
\hline $\begin{array}{l}\text { Climate change will have a major impact } \\
\text { on humans' lives in the future. }\end{array}$ & $4.77(.427)$ & $4.42(.858)$ & $4.72(.510)$ & 5.074 & .009 \\
\hline Climate change is a threat to the Earth. & $4.56(.882)$ & $4.26(1.107)$ & 4.33 (1.009) & 6.000 & .004 \\
\hline $\begin{array}{l}\text { Climate change is one of the biggest } \\
\text { challenges for humanity. }\end{array}$ & $4.54(.643)$ & $4.32(.739)$ & $4.36(.707)$ & 2.156 & .123 \\
\hline Climate change worries me. & $4.26(.938)$ & $3.97(.915)$ & $3.97(.932)$ & 4.098 & .021 \\
\hline Cronbach's Alpha & .655 & .758 & .728 & & \\
\hline
\end{tabular}

Notes: $n=38-39$; differences calculated with repeated measures ANOVA; response scale from 1 ('do not agree at all') to 5 ('totally agree').

felt insecure about climate change, but also about how to search for the desired information: "I didn't really know how to approach the search" (P04). She often followed recommendations of the used search engine or other platforms, but was mostly dissatisfied with the search results. She glanced over several websites instead of reading some parts more carefully. She had the aim "to search neutrally," which led to an excessive demand and the feeling of helplessness. In the end, this participant still felt ambivalent about the issue (P04).

Another pattern was observed within this group. P08 is taken as an extreme case. She had the highest decrease of problem awareness of the whole sample (difference $t_{c}$ to $t_{a}=2.0, t_{b}$ to $t_{a}=2.5$ on the five-point-rating scale). She had no clear research strategy but presented a high level of curiosity. She sought out surprising information with a certain uniqueness and alternative positions to traditional news media. Generally, she expressed a high interest in conspiracy theories and felt bored by things already known:

Hmm....Yeah, well, I'm really interested in conspiracy theories. I would have liked to read something about it somehow....Like where in a way something comes out that you would not have expected. Like what I have read now, it already sounded familiar to me, like what you always hear. (P08)

A high level of attraction of surprising information is clear here. This goes along with the findings of Vosoughi et al.
(2018), who identified in their big Twitter study that false stories inspired fear, disgust, and surprise in replies, and suggested that these were more likely shared because they were more novel.

What P08 and P04 have in common is that they both felt insecure because they were unable to fulfil their information desires and finish the coping process. They were unable to dissolve their inner state of tension through the use of media. Where P08 did not feel uncomfortable with the situation, P04 felt dissatisfied. This difference might be caused by different personality traits, such as tolerance of uncertainty or need for cognition, and/or different motivations such as the level of accuracy (Hart et al., 2009).

In sum, different coping strategies following Festinger's original theory could be identified here, although these were sometimes merged. A key strategy was to confirm one's former opinion on the existence of anthropogenic climate change by re-reading already known information instead of searching for new evidence. This helped to overcome cognitive discrepancies. Another dominant strategy was to seek out information about specific details named in the stimulus clip. The retrospective interviews disclosed that it was often done with the aim to refute the claims, such as to discount the source's credibility. In this way they succeeded in dissolving the negative emotional state of dissonance. Quite unexpected, many subjects also used the strategy of changing their view-meaning their climate change problem awareness decreased-although this

Table 4. Changes in problem awareness in absolute numbers of participants.

\begin{tabular}{lcrr}
\hline Problem awareness & $t_{\mathrm{a}}-\mathrm{t}_{\mathrm{b}}$ & $\mathrm{t}_{\mathrm{b}}-\mathrm{t}_{\mathrm{c}}$ & $\mathrm{t}_{\mathrm{a}}-\mathrm{t}_{\mathrm{c}}$ \\
\hline Constant & 14 & 20 & 16 \\
Increased & 5 & 13 & 5 \\
Decreased & 19 & 5 & 17 \\
\hline
\end{tabular}

Note: $\mathrm{n}=38$. 
trend weakened after the internet research phase. We further investigated those with a stable decrease and found two different patterns: the feeling of frustration and helplessness due to a lack of media literacy, and a feeling of sensation and attraction of surprising information and alternative worldviews.

\section{Limitations}

Some methodological shortcomings must be considered. First, the participants were students and thus the sample is younger, more educated, and more trained in internet usage than the German average. This might explain the relatively high level of reflected self-assessments even though this helped to gain deeper insights. As the stimulus exposure and internet research was carried out in the lab questions of external validity may arise. However, the lab was designed to be as comfortable as possible and the time given for the research process was relatively long in order to provide the most natural surroundings possible. Although we conducted post-exposure walkthrough interviews and were able to combine overt behaviour with retrospective self-assessments, we were not able to conduct unconscious behaviour and may have forced ex post sense-making processes. Finally, we were not fully successful in provoking the feeling of dissonance. On the one hand this is a clear limitation of our analyses, which ties in with a former critique of cognitive dissonance research (Donsbach, 2007) and should be considered with more attention in future studies. On the other hand, it is also a major finding of this study to confirm that climate change is a non-quested public issue in Germany (BMU \& UBA, 2019; Engels, Hüther, Schäfer, \& Held, 2013). It would be interesting to repeat the study with other science issues that have not been on the public agenda for so long and are perceived to be more ambivalent. Finally, some ethical concerns must be considered. Although the debriefing was an important component of method design, we did not measure its effect. Some participants showed a relatively strong emotional involvement during the exposure, but this was resolved in subsequent interviews.

\section{Conclusion}

With this study, we aimed to explore what affects internet users have when confronted with opinionchallenging disinformation and how they cope with their state of dissonance during an internet search. With this, we turned the usual research questions related to dissonance avoidance and confirmation biased-selection behaviour around. While prior research has often analysed how people perceive online disinformation to confirm their attitudes, the question of how users react when being confronted with opinion-challenging disinformation has been overlooked. As this is likely to happen in an online environment that can be called "dissonant public spheres" (Pfetsch, Löblich, \& Eilders, 2018), this is highly relevant. Whether or not users are 'fake news resistant,' meaning that online disinformation does not become affective in their opinion-formation processes, is seen to be a major societal challenge in the near future (Garrett, 2017).

Here, we aimed to focus on affects during exposure and coping behaviours. For this, we used an innovative, multidimensional research design which proved to be useful. It became clear that affective arousals as well as coping strategies varied individually and that overt behaviour has to be regarded against the background of individual ideas and motivations: for example, that searching for counter-arguments might be motivated by believing in an easy refutation of them. Confirming neuroscientific findings, we found that individuals felt relieved and satisfied after being able to dissolve their dissonant state and negative arousal. We also found dissatisfaction and frustration if this had not succeeded. It seems important over whether individuals were able to complete their coping process or not. Thus, unfinished coping processes might be an explanation for disenchantment with the media as well as with scientific elites. The high relevance of an adequate level of media and internet literacy is highlighted by this finding.

We were not able to analyse the effects of the disinformation stimulus in more detail in this article. However, the (short-lived) decrease of the affective attitude of problem awareness urges further analyses. Where some individuals seemed to be 'fake news resistant', others were not. Individual characteristics, such as curiosity and openness towards alternative ideas, should be investigated more deeply in this context. Further research on different typologies will be helpful when thinking about how to counteract campaigns of (mis/dis)information on science issues (lyengar \& Massey, 2019).

In addition, it seems worthwhile to analyse the relationship between the various coping strategies and selection behaviour. Thus, identifying the information sources primarily used to confirm previous opinion and which ones are used to find additional-and devaluatinginformation about the content provider. This would also include the search terms used and how relevant they are, as well as search engine hit lists for the selection of websites. For example, is information from NGOs systematically avoided and traditional journalistic information preferred? What role does social media play (Huber, Barnidge, Gil de Zúñiga, \& Liu, 2019)? These and similar questions should be answered in the future.

This study has shown how important future in-depth research is to identifying individual processes of coping with affective arousal when being confronted with disinformation on science issues.

\section{Acknowledgments}

This study was conducted in cooperation with Dr. Lars Guenther (University of Hamburg, Germany) and Dr. Arne Zillich (Friedrich Schiller University Jena, 
Germany). We thank all respondents and our students who helped to conduct the study. Furthermore, we thank the three anonymous reviewers for their constructive feedback on a previous version of the article. We acknowledge support by the German Research Foundation and the Open Access Publication Funds of the Technische Universität Braunschweig.

\section{Conflict of Interests}

The authors declare no conflict of interests.

\section{Supplementary Material}

Supplementary material for this article is available online in the format provided by the authors (unedited).

\section{References}

BMU \& UBA. (2019). Umweltbewusstsein in Deutschland 2018: Ergebnis einer repräsentativen Bevölkerungsumfrage [Environmental awareness in Germany 2018: Results of a representative population survey]. Berlin: BMU. Retrieved from https://www. bmu.de/fileadmin/Daten_BMU/Pools/Broschueren/ umweltbewusstsein_2018_bf.pdf

BMU, UBA, \& German IPCC Coordination Unit. (2017). Kernbotschaften des Fünften Sachstandsberichts des IPCC. Klimaänderung 2013: Naturwissenschaftliche Grundlagen (Teilbericht 1) [Key messages of the fifth assessment report of the IPCC. Climate change 2013: Fundamentals of natural science (Sub-report 1)]. Berlin: BMU. Retrieved from http://www.bmu.de/ fileadmin/Daten_BMU/Download_PDF/Klimaschutz/ ipcc_sachstandsbericht_5_teil_1_bf.pdf

Breyer, B., \& Bluemke, M. (2016). Deutsche Version der Positive and Negative Affect Schedule PANAS (GESIS panel) [German version of the positive and negative affect schedule PANAS (GESIS panel)]. Mannheim: GESIS. Retrieved from https://zis.gesis. org/pdfFiles/Dokumentation/Janke_+_Deutsche_ Version_der_Positive_and_Negative_Affect_ Schedule_(PANAS)_c.pdf

Cohen, J. W. (1988). Statistical power analysis for the behavioral sciences. Hillsdale, NJ: Erlbaum.

Corbin, J. M., \& Strauss, A. (1990). Grounded theory research: Procedures, canons, and evaluative criteria. Qualitative Sociology, 13(1), 3-21. https://doi.org/ 10.1007/BF00988593

D'Alessio, D., \& Allen, M. (2007). The selective exposure hypothesis and media choice processes. In R. W. Preiss (Ed.), LEA's communication series-Mass media effects research: Advances through meta-analysis (pp. 103-118). Mahwah, NJ: Erlbaum.

Davison, W. P. (1983). The third-person effect in communication. Public Opinion Quarterly, 47(1), 1-15. https://doi.org/10.1086/268763

DeWeese, T. (2002). The Heidelberg appeal. American
Policy Center. Retrieved from https://americanpolicy. org/2002/03/29/the-heidelberg-appeal

Diestel, S., \& Schmidt, K.-H. (2011). Costs of simultaneous coping with emotional dissonance and self-control demands at work: Results from two German samples. The Journal of Applied Psychology, 96(3), 643-653. https://doi.org/10.1037/a0022134

Donsbach, W. (2007). Alles nur ein Missverständnis? Wie die Kommunikationswissenschaft die Theorie der kognitiven Dissonanz adaptierte [All just a misunderstanding? How communication science adapted the theory of cognitive dissonance]. In S. Trepte, E. H. Witte, \& M. Appel (Eds.), Sozialpsychologie und Medien: Beiträge des 22. Hamburger Symposions zur Methodologie der Sozialpsychologie [Social psychology and the media: Contributions of the 22nd Hamburg symposium on methodology of social psychology] (pp. 11-34). Lengerich: Pabst Science.

Eisenegger, M. (2017). Vorwort: Digitaler Strukturwandel der Öffentlichkeit-Professionelle Informationsmedien nötiger denn je! [Editorial: Digital structural change of the public-Professional information media more necessary than ever!]. In fög-Forschungsinstitut Öffentlichkeit und Gesellschaft (Ed.), Qualität der Medien. SchweizSuisse-Svizzera. Jahrbuch 2017 [Quality of media. Switzerland. Yearbook 2017] (pp. 7-16). Basel: Schwabe. https://doi.org/10.5167/uzh-147243

Elliot, A. J., \& Devine, P. G. (1994). On the motivational nature of cognitive dissonance: Dissonance as psychological discomfort. Journal of Personality and Social Psychology, 67(3), 382-394. https://doi.org/ 10.1037/0022-3514.67.3.382

Engels, A., Hüther, O., Schäfer, M., \& Held, H. (2013). Public climate-change skepticism, energy preferences and political participation. Global Environmental Change, 23(5), 1018-1027. https://doi.org/10.1016/ j.gloenvcha.2013.05.008

Ethical Journalism Network. (n.d.). "Fake news" | deep fakes | information disorder | disinformation | misinformation | mal-information. Ethical Journalism Network. Retrieved from https://ethical journalismnetwork.org/tag/fake-news/page/3

Faul, F., Erdfelder, E., Lang, A.-G., \& Buchner, A. (2007). G*power 3: A flexible statistical power analysis program for the social, behavioral, and biomedical sciences. Behavior Research Methods, 39(2), 175-191. https://doi.org/10.3758/BF03193146

Festinger, L. (1957). A theory of cognitive dissonance. Stanford, CA: Stanford University Press.

First Draft. (n.d.). Homepage. First Draft. Retrieved from https://firstdraftnews.org

Fisher, D. R., Waggle, J., \& Leifeld, P. (2012). Where does political polarization come from? Locating polarization within the U.S. climate change debate. American Behavioral Scientist, 57(1), 70-92. https://doi.org/ $10.1177 / 0002764212463360$

Fogel, J. (2004). Internet breast health information use 
and coping among women with breast cancer. Cyberpsychology \& Behavior, 7(1), 59-63. https://doi. org/10.1089/109493104322820129

Frey, D. (1981). Postdecisional preference for decisionrelevant information as a function of the competence of its source and the degree of familiarity with this information. Journal of Experimental Social Psychology, 17(1), 51-67. https://doi.org/10.1016/ 0022-1031(81)90006-8

Garrett, R. K. (2017). The "echo chamber" distraction: Disinformation campaigns are the problem, not audience fragmentation. Journal of Applied Research in Memory and Cognition, 6(4), 370-376. https://doi. org/10.1016/j.jarmac.2017.09.011

Garrett, R. K., Carnahan, D., \& Lynch, E. K. (2013). A turn toward avoidance? Selective exposure to online political information, 2004-2008. Political Behavior, 35(1), 113-134. https://doi.org/10.1007/s11109011-9185-6

Gelfert, A. (2018). Fake news: A definition. Informal Logic, 38(1), 84-117. https://doi.org/10.22329/il. v38i1.5068

Glaser, B. G., \& Strauss, A. L. (1999). Discovery of grounded theory: Strategies for qualitative research. New York, NY: Routledge. https://doi.org/10.4324/ 9780203793206

Habermas, J. (1990). Strukturwandel der Öffentlichkeit: Untersuchungen zu einer Kategorie der bürgerlichen Gesellschaft [The structural transformation of the public sphere: An inquiry into a category of bourgeois society]. Frankfurt am Main: Suhrkamp.

Harmon-Jones, E. (2000a). Cognitive dissonance and experienced negative affect: Evidence that dissonance increases experienced negatives affect even in the absence of aversive consequences. Psychology Bulletin, 26(12), 1490-1501. https://doi.org/10.1177\% 2F01461672002612004

Harmon-Jones, E. (2000b). A cognitive dissonance theory perspective on the role of emotion in the maintenance and change of beliefs and attitudes. In N. H. Frijda, A. R. S. Manstead, \& S. Bem (Eds.), The effects of emotions upon the formation and strength of beliefs (pp. 185-211). Cambridge: Cambridge University Press. http://dx.doi.org/10.1017/ CBO9780511659904.008

Harmon-Jones, E., Harmon-Jones, C., \& Levy, N. (2015). An action-based model of cognitive-dissonance processes. Current Directions in Psychological Science, 24(3), 184-189. https://doi.org/10.1177/ 0963721414566449

Hart, W., Albarracín, D., Eagly, A. H., Brechan, I., Lindberg, M. J., \& Merrill, L. (2009). Feeling validated versus being correct: A meta-analysis of selective exposure to information. Psychological Bulletin, 135(4), 555-588. https://doi.org/10.1037/a0015701

Huber, B., Barnidge, M., Gil de Zúñiga, H., \& Liu, J. (2019). Fostering public trust in science: The role of social media. Public Understanding of Science, 28(7), 759-777. https://doi.org/10.1177/0963662519869097

lyengar, S., \& Massey, D. S. (2019). Scientific communication in a post-truth society. Proceedings of the National Academy of Sciences of the United States of America, 116(16), 7656-7661. https://doi.org/ $10.1073 /$ pnas. 1805868115

Jang, S. M. (2014). Challenges to selective exposure: Selective seeking and avoidance in a multitasking media environment. Mass Communication and Society, 17(5), 665-688. https://doi.org/10.1080/15205436. 2013.835425

Kla.tv. (n.d.). Über uns [About us]. Kla.tv. Retrieved from https://www.kla.tv/index.php?a=showaboutus

Kla.tv. (2014, December 14). Der Weltklimagipfel in Peru: Ein Betrug der fassungslos macht? [The international climate summit in Peru: A fraud that stunned?] [Video file]. Retrieved from https://www.kla.tv/4845

Knobloch-Westerwick, S., \& Kleinman, S. B. (2011). Preelection selective exposure. Communication Research, 39(2), 170-193. https://doi.org/10.1177/ 0093650211400597

Konijn, E. A. (2013). The role emotion in media use and effects. In K. E. Dill (Ed.), The Oxford handbook of media psychology (pp. 187-248). Oxford: Oxford University Press.

Kuhlthau, C. C. (1991). Inside the search process: Information seeking from the user's perspective. Journal of the American Society for Information Science, 42(5), 361-371. https://doi.org/10.1002/(SICI)10974571(199106)42:5\%3C361::AID-ASI6\%3E3.0.CO;2$\% 23$

Lünenborg, M. (2019). Affective publics. In J. Slaby \& C. von Scheve (Eds.), Affective societies (pp. 319-329). London: Routledge.

Lünenborg, M., \& Maier, T. (2018). The turn to affect and emotion in media studies. Media and Communication, 6(3), 1-4. https://doi.org/10.17645/mac.v6i3. 1732

Lünenborg, M., Maier, T., \& Töpper, C. (2018). Affekte als sozial-relationales Phänomen medialer Kommunikation: Affekttheorien für die Medienforschung nutzbar machen [Affects as a socio-relational phenomenon of media communication: How affect theories can be used in media research]. SCM Studies in Communication and Media, 7(3), 423-457. https:// doi.org/10.5771/2192-4007-2018-3-423

Papacharissi, Z. (2014). Affective publics: Sentiment, technology, and politics. New York, NY: Oxford University Press.

Pariser, E. (2011). The filter bubble: What the Internet is hiding from you. New York, NY: Penguin Press.

Pfetsch, B., Löblich, M., \& Eilders, C. (2018). Dissonante Öffentlichkeiten als Perspektive kommunikationswissenschaftlicher Theoriebildung [Dissonant public spheres as a perspective for the formation of communication theory]. Publizistik, 63(4), 477-495. https://doi.org/10.1007/s11616-018-0441-1

Scheufele, D. A., \& Krause, N. M. (2019). Science audi- 
ences, misinformation, and fake news. Proceedings of the National Academy of Sciences of the United States of America, 116(16), 7662-7669. https://doi. org/10.1073/pnas.1805871115

Simon, L., Greenberg, J. L., \& Brehm, J. (1995). Trivialization: The forgotten mode of dissonance reduction. Journal of Personality and Social Psychology, 68(2), 247-260.

Sunstein, C. (2001). Echo chambers: Bush v. Gore, impeachment, and beyond. Oxford and Princeton, NJ: Princeton University Press.

Sunstein, C. R. (2018). \#Republic: Divided democracy in the age of social media. Oxford and Princeton, NJ: Princeton University Press.

Taddicken, M. (2013). Climate change from the user's perspective. Journal of Media Psychology, 25(1), 39-52. https://doi.org/10.1027/1864-1105/a000080

Taddicken, M., \& Reif, A. (2016). Who participates in the climate change online discourse? A typology of Germans' online engagement. Communications, 41(3), 315-337. https://doi.org/10.1515/commun2016-0012

Taddicken, M., Kohout, S., \& Hoppe, I. (2019). How aware are other nations of climate change? Analyzing Germans' second-order climate change beliefs about Chinese, US American and German people. Environmental Communication, 13(8), 1-17. https://doi.org/ 10.1080/17524032.2018.1561483

The National Academies of Sciences, Engineering, and Medicine. (1998). Statement by the council of the National Academy of Sciences regarding global change petition. The National Academies of Sciences, Engineering, and Medicine. Retrieved from http://www8. nationalacademies.org/onpinews/newsitem.aspx? RecordID $=s 04201998$

van der Linden, S., Leiserowitz, A., Rosenthal, S., \& Maibach, E. (2017). Inoculating the public against misinformation about climate change. Global Challenges, 1(2), 1600008. https://doi.org/10.1002/gch2. 201600008
Vosoughi, S., Roy, D., \& Aral, S. (2018). The spread of true and false news online. Science, 359(6380), 1146-1151. https://doi.org/10.1126/science. aap9559

Watson, D., Clark, L. A., \& Tellegen, A. (1988). Development and validation of brief measures of positive and negative affect: The PANAS scales. Journal of Personality and Social Psychology, 54(6), 1063-1070. https://doi.org/10.1037/0022-3514.54.6.1063

Weeks, B. E. (2015). Emotions, partisanship, and misperceptions: How anger and anxiety moderate the effect of partisan bias on susceptibility to political misinformation. Journal of Communication, 65(4), 699-719. https://doi.org/10.1111/jcom.12164

Westen, D., Blagov, P. S., Harenski, K., Kilts, C., \& Hamann, S. (2006). Neural bases of motivated reasoning: An FMRI study of emotional constraints on partisan political judgment in the 2004 U.S. presidential election. Journal of Cognitive Neuroscience, 18(11), 1947-1958. https://doi.org/ 10.1162/jocn.2006.18.11.1947

Williams, H. T. P., McMurray, J. R., Kurz, T., \& Hugo Lambert, F. (2015). Network analysis reveals open forums and echo chambers in social media discussions of climate change. Global Environmental Change, 32, 126-138. https://doi.org/10.1016/j.gloenvcha.2015. 03.006

Wirth, W. (2013). Grundlagen emotionaler Medienwirkungen [Fundamentals of emotional media effects]. In W. Schweiger \& A. Fahr (Eds.), Handbuch Medienwirkungsforschung [Manual of media effect research] (pp. 227-246). Wiesbaden: Springer VS.

Zimmermann, F., \& Kohring, M. (2018). "Fake news" als aktuelle Desinformation: Systematische Bestimmung eines heterogenen Begriffs ["Fake news" as current disinformation: Systematic definition of a heterogeneous term]. M\&K Medien \& Kommunikationswissenschaft, 66(4), 526-541. https://doi.org/10.5771/ 1615-634X-2018-4-526

\section{About the Authors}

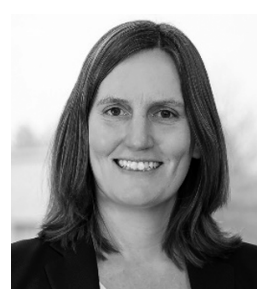

Monika Taddicken is a Professor of Communication and Media Sciences at the Technische Universität Braunschweig, Germany. She received her PhD in Communication Research from the University of Hohenheim, Germany, and is currently working on the audience's perspective of science communication. She has also published several articles on computer-mediated communication and social media, as well as on survey methodology.

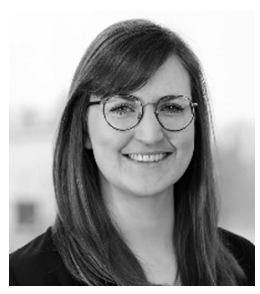

Laura Wolff is a Research Assistant at the Department of Communication and Media Sciences at the Technische Universität Braunschweig, Germany. She holds a MA degree in Media Culture from the University of Bremen, Germany. Currently, she is working on her PhD project about coping with complexity in the context of science communication and online media appropriation. 